\title{
Assessment of antibiotic resistance in Klebsiella pneumoniae exposed to sequential in vitro antibiotic treatments
}

\author{
Jeongjin Kim ${ }^{1}$, Ara Jo ${ }^{1}$, Ekachai Chukeatirote ${ }^{2}$ and Juhee Ahn ${ }^{1,3^{*}}$
}

\begin{abstract}
Background: Bacteria treated with different classes of antibiotics exhibit changes in susceptibility to successive antibiotic treatments. This study was designed to evaluate the influence of sequential antibiotic treatments on the development of antibiotic resistance in Klebsiella pneumoniae associated with $\beta$-lactamase and efflux pump activities.

Methods: The antibiotic susceptibility, $\beta$-lactamase activity, and efflux activity were determined in K. pneumoniae grown at $37^{\circ} \mathrm{C}$ by adding initial $(\mathrm{O}$ h) and second antibiotics ( 8 or $12 \mathrm{~h}$ ). Treatments include control (CON; no first and second antibiotic addition), no initial antibiotic addition followed by $1 \mathrm{MIC}$ ciprofloxacin addition (CON-CIP), no initial antibiotic addition followed by 1 MIC meropenem addition (CON-MER), initial 1/4 MIC ciprofloxacin addition followed by no antibiotic addition (1/4CIP-CON), initial 1/4 MIC ciprofloxacin addition followed by 1 MIC ciprofloxacin addition (1/4CIP-CIP), and initial 1/4 MIC ciprofloxacin addition followed by 1 MIC meropenem addition (1/4CIP-MER).
\end{abstract}

Results: Compared to the CON, the initial addition of $1 / 4$ MIC ciprofloxacin inhibited the growth of $K$. pneumoniae throughout the incubation period. The ciprofloxacin treatments (CON-CIP and 1/4CIP-CIP) showed significant reduction in the number of $K$. pneumoniae cells compared to meropenem (CON-MER and 1/4CIP-MER). The 1/4CIP-CIP achieved a further 1 log reduction of K. pneumoniae, when compared to the 1/4CIP-CON and 1/CIP-MER. The increase in sensitivity of K. pneumoniae to cefotaxime, kanamycin, levofloxacin, nalidixic acid was observed for CON-CIP. Noticeable cross-resistance pattern was observed at the 1/4CIP-CIP, showing the increased resistance of K. pneumoniae to chloramphenicol, ciprofloxacin, kanamycin, levofloxacin, nalidixic acid norfloxacin, sulphamethoxazole/trimethoprim, and tetracycline. The levels of $\beta$-lactamase activities were estimated to be $8.4 \mu \mathrm{mol} / \mathrm{min} / \mathrm{ml}$ for CON, $7.7 \mu \mathrm{mol} / \mathrm{min} /$ $\mathrm{ml}$ for $1 / 4 \mathrm{CIP}-\mathrm{CON}$ and as low as $2.9 \mathrm{\mu mol} / \mathrm{min} / \mathrm{ml}$ for CON-CIP. Compared to the absence of phenylalanine-arginine$\beta$-naphthylamide $(P A \beta N)$, the fluorescence intensity of EtBr was increased in $K$. pneumoniae cells treated at the CON, CON-CIP, and CON-MER in the presence of PABN. However, the efflux pump activity remained in K. pneumoniae cells treated at the 1/CIP, 1/CIP-CIP, and 1/CIP-MER in the presence of PABN.

Conclusion: The results suggest that the pre-exposed antibiotic history, treatment order, and concentrations influenced the development of multiple antibiotic resistant associated with $\beta$-lactamase and efflux pump activities. This study highlights the importance of antibiotic treatment conditions, which would be taken into consideration when new antibiotic strategy is designed to prevent antibiotic resistance.

Keywords: $\beta$-Lactamase, Efflux pump system, Meropenem, Ciprofloxacin, Antibiotic resistance

\footnotetext{
*Correspondence: juheeahn@kangwon.ac.kr

${ }^{1}$ Department of Medical Biomaterials Engineering, Kangwon National

University, Chuncheon, Gangwon 24341, South Korea

Full list of author information is available at the end of the article
}

(c) The Author(s) 2016. This article is distributed under the terms of the Creative Commons Attribution 4.0 International License (http://creativecommons.org/licenses/by/4.0/), which permits unrestricted use, distribution, and reproduction in any medium, provided you give appropriate credit to the original author(s) and the source, provide a link to the Creative Commons license, and indicate if changes were made. The Creative Commons Public Domain Dedication waiver (http://creativecommons.org/ publicdomain/zero/1.0/) applies to the data made available in this article, unless otherwise stated. 


\section{Background}

The overuse, underuse, and misuse of antibiotics have become major causes of the development of antibiotic resistance in bacteria [1]. The emergence and spread of antibiotic-resistant bacteria has been a growing concern over the last decade, which can lead to serious clinical and public health problems. Klebsiella pneumoniae, an opportunistic pathogen, is mainly responsible for nosocomial infections with high morbidity and mortality [2]. Recently, the rapid emergence of extended-spectrum $\beta$-lactamase (ESBL) producing $K$. pneumoniae has significantly increased the risk of developing serious nosocomial and community-acquired infections worldwide $[3,4]$. Furthermore, multidrug-resistant $K$. pneumoniae strains can cause treatment failure with current antibiotic therapy [2].

The proposed resistance mechanisms of K. pneumoniae against different classes of antibiotics include release of antibiotic-inactivating enzymes, modification of antibiotic target sites, change in membrane permeability, activation of efflux pump systems, and alteration of metabolic pathways [2,5]. Among these mechanisms, the enzymatic degradation and efflux pump systems play an important role in the development of multidrug resistance in K. pneumoniae [6]. K. pneumoniae strains produce enzymes, including extended-spectrum $\beta$-lactamases, metallo- $\beta$-lactamases, oxacillinases, and carbapenemases, that can degrade $\beta$-lactam antibiotics. The efflux pumps, belonging to the resistance-nodulation-division (RND) family, can extrude amphiphilic and charged antibiotics such as $\beta$-lactams, fluoroquinolones, and aminoglycosides [2].

The sequential and combination antibiotic therapies have currently been used to reduce not only the evolution of multidrug resistant bacteria but also the levels of antibiotics used in the treatment of bacterial infection [7-9]. The decreased selection pressure occurs when antibiotics are treated in appropriate order, which can prevent the emergence and spread of multidrug resistance [10]. From the practical viewpoint of antibiotic effectiveness, however, there is an important challenging question of whether the treatment history can cause potential carry-over effects on the additional antibiotic therapy. The pre-exposure to antibiotics influences the acquisition of resistance to second-line antibiotics [11]. The beneficial and adverse effects of current therapeutic approaches for treating bacterial infections are still under debate. Therefore, the objective of this study was to evaluate the impact of sequential antibiotic treatments on the antibiotic susceptibility and resistance mechanisms of $K$. pneumoniae in association with $\beta$-lactamase and efflux pump activities.

\section{Methods}

Bacterial strain and culture condition

Strain of K. pneumoniae ATCC 23357 was purchased from American Type Culture Collection (ATCC, Manassas, VA, USA). The strain was cultured in trypticase soy broth (TSB; BD, Becton, Dickinson and Co., Sparks, MD, USA) at $37{ }^{\circ} \mathrm{C}$ for $18 \mathrm{~h}$. After cultivation, the culture was centrifuged at $3000 \times g$ for $20 \mathrm{~min}$ at $4{ }^{\circ} \mathrm{C}$. The harvested cells were washed twice with phosphate-buffered saline (PBS, pH 7.2) and diluted to $10^{8} \mathrm{CFU} / \mathrm{ml}$ for assays.

\section{Antibiotic susceptibility assay}

The susceptibility of K. pneumoniae to ciprofloxacin and meropenem was evaluated according to the Clinical Laboratory Standards Institute (CLSI) procedure with slight modification [12]. All antibiotics used in this study were purchased from Sigma Chemicals (St. Louis, MO, USA). Antibiotic stock solutions were prepared by dissolving in glacial acetic acid for ciprofloxacin and distilled water for meropenem to obtain a final concentration of $10.24 \mathrm{mg} /$ $\mathrm{ml}$. The stock solutions of ciprofloxacin and meropenem (100 $\mu \mathrm{l}$ each) were serially (1:2) diluted to concentrations ranging from 2 to $0 \mu \mathrm{g} / \mathrm{ml}$ with TSB in 96-well flat-bottomed polystyrene microtiter plates (BD Falcon, San Jose, CA, USA). The test strain was inoculated at $10^{5} \mathrm{CFU} /$ $\mathrm{ml}$ and incubated at $37{ }^{\circ} \mathrm{C}$ for $18 \mathrm{~h}$. Minimum inhibitory concentrations (MICs) of ciprofloxacin and meropenem were defined as the lowest concentration of each antibiotic at which no visible cell growth was observed.

\section{Dynamic time-kill curve analysis}

Time-kill curve assay was carried out to determine the antibiotic activities of ciprofloxacin and meropenem against $K$. pneumoniae using a sequential treatment scheme as described in Table 1 . The initial population $\left(10^{5} \mathrm{CFU} / \mathrm{ml}\right)$ of $\mathrm{K}$. pneumoniae was inoculated at $37{ }^{\circ} \mathrm{C}$ in TSB treated with (Treatments 1, 2, and 3) and without antibiotic (Treatments 4, 5, and 6). After being reached an optical density (OD) of 0.5 , the non-adapted and ciprofloxacin-adapted K. pneumoniae cells were further treated with no (Treatments 1 and 4 ) and the increased concentrations of ciprofloxacin (Treatments 2 and 5) and meropenem (Treatments 3 and 6). The survival curves were measured at $600 \mathrm{~nm}$ at every $4 \mathrm{~h}$ interval throughout the incubation period. The cultured cells were collected for further analyses, including bacterial enumeration, disk diffusion, lactamase activity, and cartwheel tests.

\section{Microbial analysis}

The collected cells were serially diluted (1:10) with PBS and then plated on trypticase soy agar (TSA) using an Autoplate Spiral Plating System (Spiral Biotech Inc., 
Table 1 Sequential antibiotic treatments used in this study

\begin{tabular}{|c|c|c|c|c|}
\hline \multirow[t]{2}{*}{ Treatment } & \multicolumn{2}{|c|}{ Antibiotic addition (h) } & \multirow[t]{2}{*}{ Abbreviation } & \multirow[t]{2}{*}{ Description } \\
\hline & $\mathrm{Oh}$ & 8 or $12 h$ & & \\
\hline 1 & No $(0)$ & No (8) & CON & No first and second antibiotic addition \\
\hline 2 & No $(0)$ & $1 \mathrm{MIC} \mathrm{CIP} \mathrm{(8)}$ & CON-CIP & No initial antibiotic addition followed by 1 MIC ciprofloxacin addition \\
\hline 3 & No $(0)$ & 1 MIC MER (8) & CON-MER & No initial antibiotic addition followed by $1 \mathrm{MIC}$ meropenem addition \\
\hline 4 & 1/4 MIC CIP (0) & No (12) & $1 / 4 \mathrm{CIP}-\mathrm{CON}$ & Initial 1/4 MIC ciprofloxacin followed by no antibiotic addition \\
\hline 5 & 1/4 MIC CIP (0) & 1 MIC CIP (12) & $1 / 4 \mathrm{CIP}-\mathrm{CIP}$ & Initial 1/4 MIC ciprofloxacin followed by 1 MIC ciprofloxacin addition \\
\hline 6 & 1/4 MIC CIP (0) & 1 MIC MER (12) & 1/4CIP-MER & Initial 1/4 MIC ciprofloxacin followed by 1 MIC meropenem addition \\
\hline
\end{tabular}

CON, CIP, and MER denote no antibiotic addition, ciprofloxacin, and meropenem, respectively

Norwood, MA, USA). The plates were incubated at $37^{\circ} \mathrm{C}$ for 24-48 h to enumerate viable cells using a QCount Colony Counter (Spiral Biotech Inc.). Log reduction $\left(N_{\mathrm{TRT}} / N_{\mathrm{CON}}\right)$ was calculated for each treatment as compared to the control (CON). $N_{\mathrm{CON}}$ and $N_{\text {TRT }}$ represent the numbers of control and treatments after incubation, respectively.

\section{Disk-diffusion assay}

The antibiotic susceptibility of cultured K. pneumoniae was determined by the disk-diffusion test. The cultured cells were evenly spread-plated on TSA and then allowed to dry for $5 \mathrm{~min}$. Antibiotic disks (Becton, Dickinson and Company, NJ, USA), including cefotaxime (CTX; $30 \mu \mathrm{g}$ ), chloramphenicol (CHL; $30 \mu \mathrm{g})$, ciprofloxacin (CIP; $5 \mu \mathrm{g}$ ), kanamycin (KAN; $30 \mu \mathrm{g}$ ), levofloxacin (LEV; $5 \mu \mathrm{g}$ ), nalidixic acid (NAL; $30 \mu \mathrm{g}$ ), norfloxacin (NOR; $10 \mu \mathrm{g}$ ), sulphamethoxazole/trimethoprim (S/T; $25 \mu \mathrm{g}$ ), and tetracycline (TET; $30 \mu \mathrm{g}$ ), were placed on the surface of the agar using sterilized forceps. After incubation at $38{ }^{\circ} \mathrm{C}$ for $24 \mathrm{~h}$, the diameters of inhibition zone were measured using a metric ruler.

\section{$\beta$-Lactamase activity assay}

The $\beta$-lactamase activity was evaluated using a nitrocefin hydrolysis assay [13]. The cultured cells were centrifuged at $3000 \times g$ for $20 \mathrm{~min}$ at $4{ }^{\circ} \mathrm{C}$ to collect cell-free supernatants. The cell-free supernatants were mixed with $20 \mu \mathrm{l}$ of $1.5 \mathrm{mM}$ nitrocefin (Biovision, Inc., CA, USA) and incubated at $37{ }^{\circ} \mathrm{C}$. The absorbance was measured every $5 \mathrm{~min}$ up to $1 \mathrm{~h}$ at $515 \mathrm{~nm}$ [14].

\section{Ethidium bromide (EtBr)-agar cartwheel assay}

The cultured $K$. pneumoniae cells were centrifuged at $3000 \times g$ for $20 \mathrm{~min}$ at $4{ }^{\circ} \mathrm{C}$, rinsed twice with PBS, and then suspended in PBS with and without efflux pump inhibitor (phenylalanine-arginine- $\beta$-naphthylamide; PA $\beta N, 8 \mu \mathrm{g} / \mathrm{ml})[15,16]$. The prepared cells were swabbed on EtBr-agar plates containing $\operatorname{EtBr}(1 \mu \mathrm{g} / \mathrm{ml})$ and incubated at $37{ }^{\circ} \mathrm{C}$ for $18 \mathrm{~h}$. After incubation, the swabbed
EtBr-agar plates exposed to UV light were photographed using a Gel-doc XR System (Bio-Rad, Hertfordshire, UK).

\section{Statistical analysis}

All analyses were conducted in duplicates for three replicates. Data were analyzed by the Statistical Analysis System (SAS) software. The General Linear Model (GLM) and least significant difference (LSD) procedures were used to compare treatments at $\mathrm{p}<0.05$.

\section{Results}

Effect of serial antibiotic treatments on the viability and antibiotic susceptibility

The MIC values of ciprofloxacin and meropenem were 0.03 and $0.06 \mu \mathrm{g} / \mathrm{ml}$, respectively. The survival of $K$. pneumoniae was observed during the sequential antibiotic treatments (Fig. 1). The growth of $K$. pneumoniae was retarded by $1 / 4$ MIC ciprofloxacin, showing that the nonand ciprofloxacin-treated $K$. pneumoniae cells reached OD of 0.5 after 8 and $12 \mathrm{~h}$ of incubation, respectively. The antibiotic effects of ciprofloxacin and meropenem on the growth of K. pneumoniae was noticeable in the nonadapted cells (CON-CIP and CON-MER) compared to the ciprofloxacin-adapted cells (1/4CIP-CIP and 1/4CIPMER). The number of viable $K$. pneumoniae cells under 1/4CIP-CIP was significantly reduced by $1.8 \mathrm{log}$, followed by CON-CIP and 1/4CIP-MER (Fig. 2). The least reduction in K. pneumoniae cells was observed at the CONMER. The reduction rate increased with increasing the concentration of CIP to $0.03 \mu \mathrm{g} / \mathrm{ml}$ (1/4CIP-CIP), while no significant reduction was observed for the $1 / 4 \mathrm{CIP}$ MER switched from CIP to MER at the second treatment. The antibiotic resistance acquisition was evaluated in $K$. pneumoniae exposed to sequential antibiotic treatments (Fig. 3). The susceptibilities of $K$. pneumoniae to different classes of antibiotics varied in the treatments. The 1/4CIP-CIP treatment exhibited the decreased susceptibility to all antibiotics with exception of CTX, showing small clear zones $(<10 \mathrm{~cm})$. The enhanced susceptibility to all antibiotics tested was observed at the 


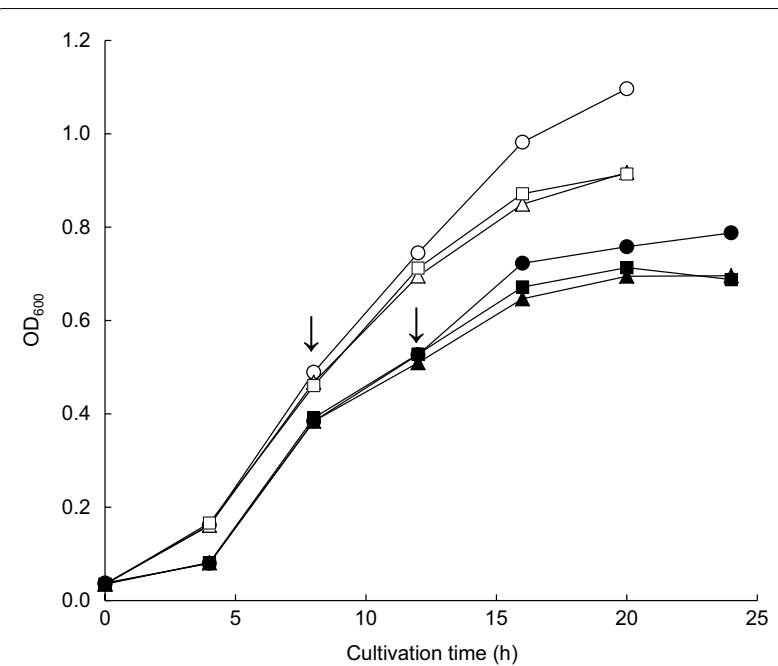

Fig. 1 Survival of Klebsiella pneumonia exposed to sequential antibiotics (CON, open circle; CON-CIP, open triangle; CON-MER, open square; 1/4CIP-CON, closed circle; 1/4CIP-CIP, closed triangle; 1/4CIP-MER, closed square). Arrow indicates the addition time

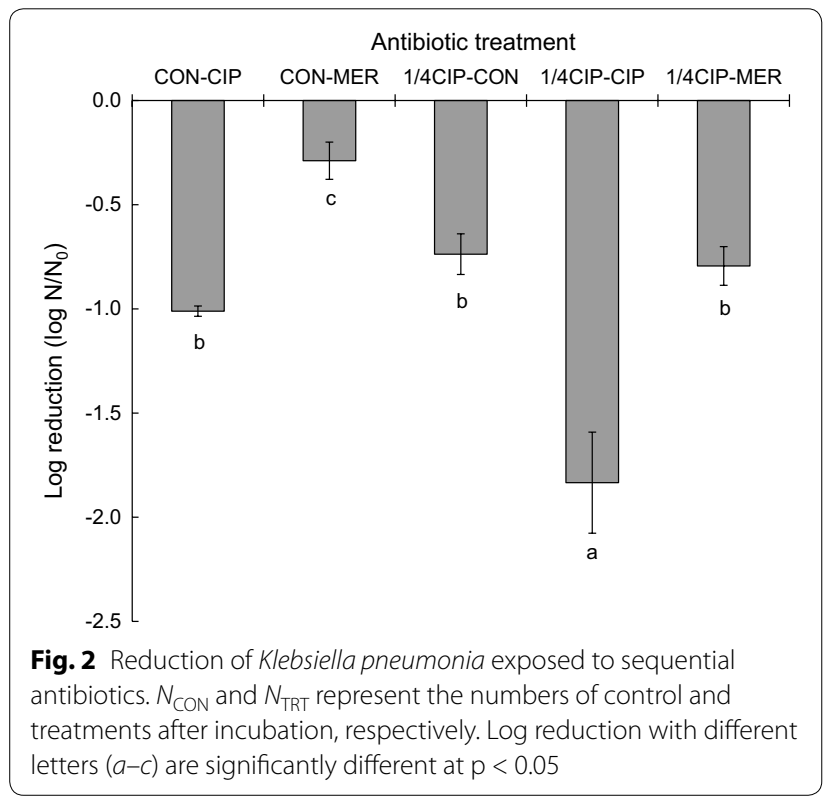

CON-CIP treatment, while the decreased susceptibilities to CIP and TET were observed at the treatments, CONMER, 1/4CIP-CON, and 1/4CIP-MER. The treatments, CON-MER and 1/4CIP-MER, showed the similar resistance pattern as the $\mathrm{CON}$.

\section{Effect of sequential antibiotic treatments on $\beta$-lactamase and efflux pump activities}

The $\beta$-lactamase activities were measured in K. pneumoniae cultured at sequential antibiotic treatments (Fig. 4). The highest $\beta$-lactamase activity was observed for the

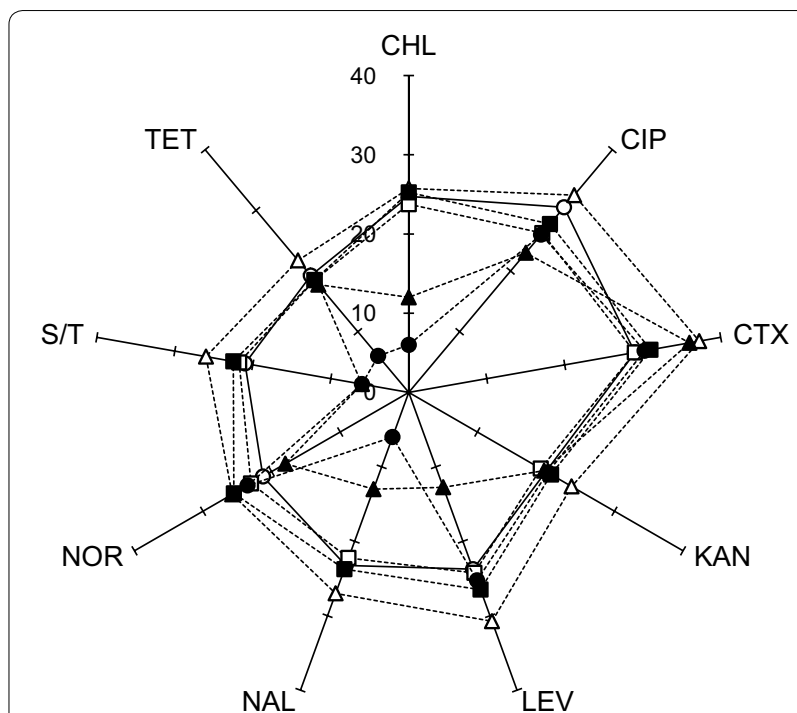

Fig. 3 Radar plot of antibiotic resistance profiles (disk diffusion in $\mathrm{cm}$ ) of Klebsiella pneumonia exposed to sequential antibiotics (CON, open circle; CON-CIP, open triangle; CON-MER, open square; 1/4CIP-CON, closed circle; 1/4CIP-CIP, closed triangle; 1/4CIP-MER, closed square). Antibiotic discs include chloramphenicol ( $\mathrm{CHL} ; 30 \mu \mathrm{g})$, ciprofloxacin (CIP; $5 \mu \mathrm{g})$, cefotaxime (CTX; $30 \mu \mathrm{g})$, kanamycin (KAN; $30 \mu \mathrm{g})$, levofloxacin (LEV; $5 \mu \mathrm{g}$ ), nalidixic acid (NAL; $30 \mu \mathrm{g}$ ), norfloxacin (NOR; $10 \mu \mathrm{g})$, sulphamethoxazole/trimethoprim $(\mathrm{S} / \mathrm{T} ; 25 \mu \mathrm{g})$, and tetracycline $(\mathrm{TET} ; 30 \mu \mathrm{g})$

CON $(8.4 \mu \mathrm{mol} / \mathrm{min} / \mathrm{ml})$, followed by $1 / 4 \mathrm{CIP}-\mathrm{CON}$ $(7.7 \mu \mathrm{mol} / \mathrm{min} / \mathrm{ml})$ and CON-MER $(6.0 \mu \mathrm{mol} / \mathrm{min} / \mathrm{ml})$.

The efflux activity of $K$. pneumoniae in the absence and presence of efflux pump inhibitor (EPI; PA $\beta N$ ) was evaluated on the EtBr-agar plates (Fig. 5). The efflux pump activity of $K$. pneumoniae was observed at all treatments in the absence of $P A \beta N$, showing the decreased fluorescence intensity (Fig. 5a). The increased EtBr accumulation was observed in the presence of $\mathrm{PA} \beta \mathrm{N}$ at the CON, CON-CIP, and CON-MER, while relatively low EtBr accumulation was observed at the 1/4CIP-CON, 1/4CIP-CIP, and 1/4CIP-MER (Fig. 5b). The efflux pump activity in $K$. pneumoniae cells treated at the 1/4CIP-CIP, $1 / 4$ CIP-CIP, and 1/4CIP-MER was not reduced by the $\mathrm{PA} \beta \mathrm{N}$, suggesting that the EPI-insensitive efflux systems were activated in $K$. pneumoniae cells under sublethal concentration of ciprofloxacin.

\section{Discussion}

This study describes the effect of sequential antibiotic treatments on the development of antibiotic resistance in K. pneumoniae. Pathogenic bacteria exposed to different levels and various classes of antibiotics can exhibit various susceptibility to additional antibiotic treatments. However, few studies have been focused on the development of antibiotic resistance during the sequential 


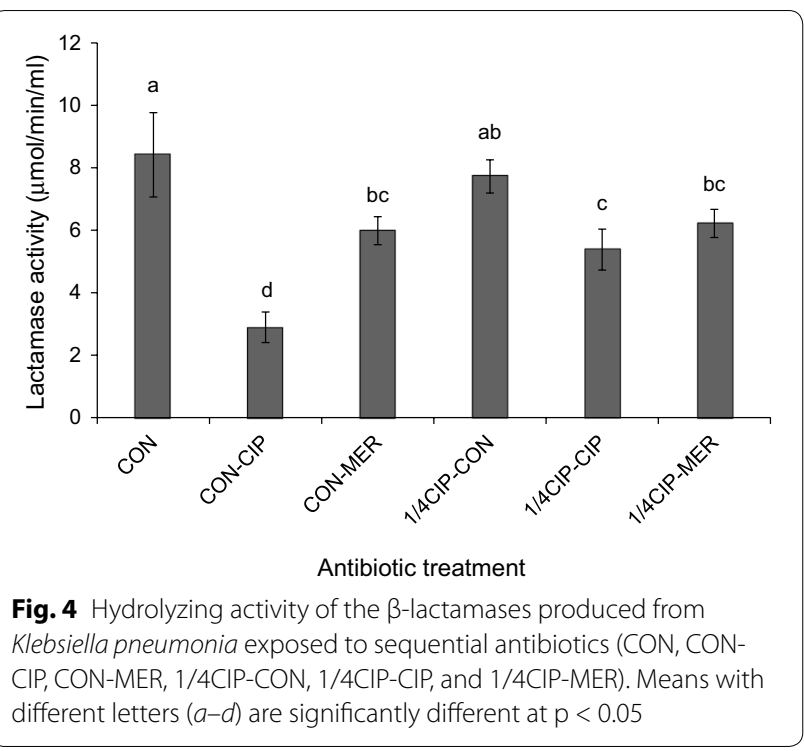

antibiotic treatments [11]. Thus, this study highlights the pre-exposed antibiotic history as an important factor for the evolution of antibiotic resistance.

The CON-CIP was more effectively reduced the number of $K$. pneumoniae cells than the CON-MER, while no significant difference was observed between 1/4CIPCON and 1/4CIP-MER (Fig. 2). The results indicate that meropenem was less effective against $K$. pneumoniae than ciprofloxacin. The lack of antibacterial activity of meropenem might be due to its short elimination half-life [17]. The successive ciprofloxacin treatment (1/4CIP-CIP) showed strong antibacterial activity against $K$. pneumoniae (Fig. 2). However, the cells exposed to 1/4CIP-CIP treatment induced were significantly resistant to different classes of antibiotics such as CHL, CIP, LEV, NAL, and $\mathrm{S} / \mathrm{T}$, known as cross-resistance induction (Fig. 3). This suggests that the sequential single-antibiotic therapy at different levels can lead to the emergence of antibiotic resistant bacteria due to the phenotypic adaptation [18]. Previous studies have reported that antibiotic monotherapy and combination therapy are the main causes of narrow- and broad-spectrum resistance, respectively [9]. The concentration of ciprofloxacin treated after the initial CIP exposure might be insufficient to suppress the development of antibiotic resistance [19]. The sequential antibiotic treatment, specifically $1 / 4$ CIP-CIP, can possibly cause a change in antibiotic resistance. This might be attributed to the mode of action of antibiotics, including time- and concentration-dependent activities. The timedependent antibiotics include $\beta$-lactams and carbapenems, characterized by slow antibiotic activity according to exposure time above MIC $[20,21]$. Ciprofloxacin is referred to as concentration-dependent antibiotic, showing antibiotic activity at high concentration [22]. Due to the bacterial adaptation, the sequential treatment of homogeneous antibiotic can reduce the susceptibility to same and different classes of antibiotics [19, 23]. Homogeneous treatment increases bacterial fitness and selection pressure, resulting in the development of antibiotic resistance $[24,25]$.

The strain of K. pneumoniae used in this study was intrinsically resistant to ampicillin (MIC $>256 \mu \mathrm{g} / \mathrm{ml}$ ), piperazine (MIC $>16 \mu \mathrm{g} / \mathrm{ml}$ ), cephalotin (MIC $>32 \mu \mathrm{g} /$ $\mathrm{ml})$, and cefoxitin $(\mathrm{MIC}>16 \mu \mathrm{g} / \mathrm{ml})$, resulted from the production of $\beta$-lactamases [26]. No significant change in $\beta$-lactamase activities was observed for $1 / 4 \mathrm{CIP}-\mathrm{CON}$ when compared to the $\mathrm{CON}$, while the $\beta$-lactamase
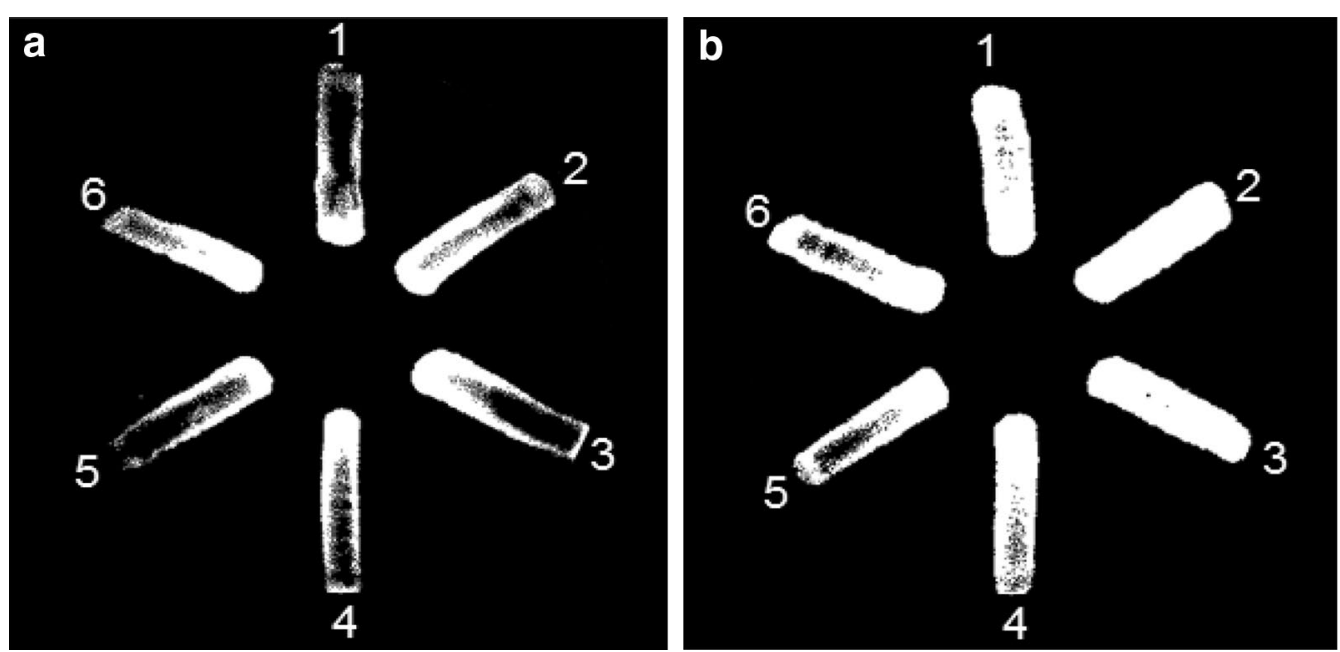

Fig. 5 Accumulation and efflux activity of Klebsiella pneumonia on EtBr agar plates containing without (a) and with (b) efflux pump inhibitor (PAßN). (1 CON; 2 CON-CIP; 3 CON-MER; 4, 1/4CIP-CON; 5 1/4CIP-CIP; 61 1/4CIP-MER) 
activities were significantly decreased at the CONCIP, CON-MER, 1/4CIP-CIP, and 1/4CIP-MER. The decrease in lactamase activity suggest that relatively fewer viable cells were observed at the treatments compared to the CON and the antibiotics used may act as a lactamase inhibitor [27]. K. pneumoniae cells exposed to CON-CIP showed the increased susceptibility to CTX (Fig. 3), which corresponds to the significant reduction in $\beta$-lactamase activity treated at CON-CIP $(2.9 \mu \mathrm{mol} / \mathrm{min} /$ ml) (Fig. 4). The mechanisms of resistance to $\beta$-lactam antibiotics include not only the increase in $\beta$-lactamasesmediated hydrolysis but also the decrease in uptake through porin channels and the increase in efflux pump activity $[6,28]$. The alteration in porin channel results in the decrease in membrane permeability to antibiotics such as $\beta$-lactams and quinolones, but not aminoglycosides that can enter the outer membrane through lipopolysaccharide (LPS) uptake system [19]. The results explain that the susceptibilities of K. pneumoniae cells grown at all treatments to KAN were constant regardless of the levels of $\beta$-lactamase activities (Fig. 3). Carbapenems such as imipenem and meropenem are stable to $\beta$-lactamases that can hydrolyze $\beta$-lactams [28-30]. The production of $\beta$-lactamases can contribute to the hydrolysis, resulting in the enhanced resistance to $\beta$-lactam antibiotics that cannot reach penicillin binding protein (PBP) [26]. This is in good agreement with the result of antibiotic susceptibility that $K$. pneumoniae possesses high intrinsic resistance to ampicillin (MIC $>256 \mu \mathrm{g} / \mathrm{ml}$ ).

The efflux pump systems competitively expel substrates, which plays an important role in the development of multidrug resistance [2]. The specific substrates for efflux pumps in K. pneumoniae treated at 1/4CIP-CIP and 1/4CIP-CIP may include CHL, TET, NOR, NAL, and LEV, corresponding the enhanced multiple antibiotic resistance in disk-diffusion assay in Fig. 3 . The intracellular concentrations of antibiotics substrates in bacteria are directly reduced by active efflux pump systems, leading to the decreased antibiotic susceptibility [31]. In other words, the inhibition of efflux pumps can restore antibiotic susceptibility in resistant bacteria, suggesting the EPI can be a possible control method against antibioticresistant bacteria [32-34]. The activation of efflux pumps is associated with the fast-acting antibiotic mechanism at the early stage of antibiotic resistance development [19]. The substrate-dependent efflux pump systems may contribute to cross-resistance to different classes of antibiotics [35].

\section{Conclusions}

This study highlights the influence of using sequential antibiotic treatment on the development of antibiotic resistance in K. pneumoniae. The difference in antibiotic activity against $K$. pneumoniae might be due to the time- and concentration-dependent modes of action of meropenem and ciprofloxacin, respectively. The antibiotic resistance mechanisms can occur within a short time in association with lactamase production, membrane permeability, and efflux pump activity. The efflux pump activities in $K$. pneumoniae cells treated at 1/4CIP-CON, 1/4CIP-CIP, and 1/4CIP-MER were still observed in the presence of $P A \beta N$, indicating that various types of substrate-dependent efflux pumps exist to reduce the intracellular concentrations of antibiotics. The induced efflux pump activity are responsible for the increased antibiotic resistance in $K$. pneumoniae. The most significant finding in this study was that $K$. pneumoniae treated with sequential antibiotics, specifically 1/4CIP-CIP, showed reduced susceptibility towards CHL, NOR, NAL, and LEV, leading to the multiple antibiotic resistance. Therefore, antibiotic therapies should take into account the history of pre-exposed antibiotics to prevent the development of antibiotic resistance. Further studies are needed to assess the risk of antibiotic resistance in sequential and combination antibiotic therapies, which is essential to design an effective strategy for controlling multiple antibiotic resistant bacteria.

\section{Abbreviations \\ ESBL: extended-spectrum $\beta$-lactamase; MIC: minimum inhibitory concentra- tion; CIP: ciprofloxacin; MER: meropenem; CTX: cefotaxime; $\mathrm{CHL}$ : chlo- ramphenicol; KAN: kanamycin; LEV: levofloxacin; NAL: nalidixic acid; NOR: norfloxacin; S/T: sulphamethoxazole/trimethoprim; TET: tetracycline; CFU: colony forming unit; EtBr: ethidium bromide; EPI: efflux pump inhibitor; PAßN: phenylalanine-arginine- $\beta$-naphthylamide.}

\section{Authors' contributions}

$\mathrm{JK}$ and $\mathrm{AJ}$ conducted all experiments and EC contributed to the writing and preparation of the manuscript. JA contributed to the experimental design, data interpretation, and manuscript writing. All authors read and approved the final manuscript.

\section{Author details \\ ${ }^{1}$ Department of Medical Biomaterials Engineering, Kangwon National University, Chuncheon, Gangwon 24341, South Korea. ${ }^{2}$ School of Science, Mae Fah Luang University, Chiang Rai 57100, Thailand. ${ }^{3}$ Institute of Bioscience and Biotechnology, Kangwon National University, Chuncheon, Gangwon 24341 , South Korea.}

\section{Acknowledgements}

Not applicable.

Competing interests

The authors declare that they have no competing interests.

Availability of data and materials

The data supporting the conclusions are included within the manuscript.

\section{Funding}

This work supported by a grant of the Korea Health Technology R\&D Project through the Korea Health Industry Development Institute (KHIDI), funded by the Ministry of Health \& Welfare, Republic of Korea (Grant number: HI15C-1798-000016). 
Received: 18 August 2016 Accepted: 13 November 2016 Published online: 09 December 2016

\section{References}

1. Odonkor ST, Addo KK. Bacterial resistance to antibiotics: recent trends and challenges. Int J Bio Med Res. 2011;2(4):1204-10.

2. HQ Zhong, Zhang S, Pan H, Cai T. Influence of induced ciprofloxacin resistance on efflux pump activity of Klebsiella pneumoniae. J Zhejiang Univ Sci B. 2013;14(9):837-43.

3. Brinkworth AJ, Hammer CH, Olano LR, Kobayashi SD, Chen L, Kreiswirth $\mathrm{BN}$, et al. Identification of outer membrane and exoproteins of carbapenem-resistant multilocus sequence Type 258 Klebsiella pneumoniae. PLoS ONE. 2015;10(4):e0123219.

4. Latifpour M, Gholipour A, Damavandi MS. Prevalence of extended-spectrum beta-lactamase-producing Klebsiella pneumoniae isolates in nosocomial and community-acquired urinary tract infections. Jundishapur J Microbiol. 2016;9(3):e31179.

5. Tenover FC. Mechanisms of antimicrobial resistance in bacteria. Am J Med. 2006;119(6A):S3-10.

6. Pages J-M, Lavigne J-P, Leflon-Guibout V, Marcon E, Bert F, Noussair L, et al. Efflux pump, the masked side of $\beta$-lactam resistance in Klebsiella pneumoniae clinical isolates. PLoS ONE. 2009:4(3):e4817.

7. Nichol D, Jeavons P, Fletcher AG, Bonomo RA, Maini PK, Paul JL, et al. Steering evolution with sequential therapy to prevent the emergence of bacterial antibiotic resistance. PLoS Comput Biol. 2015;11(9):e1004493.

8. Perron GG, Kryazhimskiy S, Rice DP, Buckling A. Multidrug therapy and evolution of antibiotic resistance: when order matters. Appl Environ Microbiol. 2012;78(17):6137-42.

9. Vestergaard M, Paulander W, Marvig RL, Clasen J, Jochumsen N, Molin $\mathrm{S}$, et al. Antibiotic combination therapy can select for broad-spectrum multidrug resistance in Pseudomonas aeruginosa. Int J Antimicrob Agent. 2016;47(1):48-55

10. Warren DK, Hill HA, Merz LR, Kollef MH, Hayden MK, Fraser VJ, et al. Cycling empirical antimicrobial agents to prevent emergence of antimicrobial-resistant Gram-negative bacteria among intensive care unit patients. Crit Care Med. 2004;32(12):2450-6.

11. Gould IM, MacKenzie FM. Antibiotic exposure as a risk factor for emergence of resistance: the influence of concentration. J Appl Microbiol. 2002;92:78S-84S

12. CLSI. Methods for dilution antimicrobial susceptibility tests for bacteria that grow aerobically. Approved standard M07-A9, 9th edn. Wayne, PA: Clinical and Laboratory Standards Institute; 2012

13. Matsumoto Y, Hayama K, Sakakihara S, Nishino K, Noji H, lino R, et al. Evaluation of multidrug efflux pump inhibitors by a new method using microfluidic channels. PLOS ONE. 2011;6(4):e18547.

14. Sharma S, Ramnani P, Virdi JS. Detection and assay of $\beta$-lactamases in clinical and non-clinical strains of Yersinia enterocolitica biovar 1A. J Antimicrob Chemother. 2004;54(2):401-5.

15. Costa SS, Falcão C, Viveiros M, Machado D, Martins M, Melo-Cristino J, et al. Exploring the contribution of efflux on the resistance to fluoroquinolones in clinical isolates of Staphylococcus aureus. BMC Microbiol. 2011;11(1):1-12.

16. Martins M, Viveiros M, Couto I, Costa SS, Pacheco T, Fanning S, et al. Identification of efflux pump-mediated multidrug-resistant bacteria by the ethidium bromide-agar cartwheel method. In Vivo. 2011:25(2):171-8.

17. Walsh F. Doripenem: a new carbapenem antibiotic a review of comparative antimicrobial and bactericidal activities. Ther Clin Risk Manag. 2007;3(5):789-94.

18. var der Horst MA, Schuurmans JM, Smid MC, Koenders BB, ter Kuile BH. De vovo acquisition of resistance to three antibiotics by Escherichia coli. Microb Drug Resist. 2011;17(2):141-7.
19. Wu BM, Sabarinath SN, Rand K, Johnson J, Derendorf H. Suppression of ciprofloxacin-induced resistant Pseudomonas aeruginosa in a dynamic kill curve system. Int J Antimicrob Agent. 2011;37(6):519-24.

20. Williamson R, Tomasz A. Inhibition of cell wall synthesis and acylation of the penicillin binding proteins during prolonged exposure of growing Streptococcus pneumoniae to benzylpenicillin. Eur J Biochem. 1985:151(3):475-83.

21. Jacobs MR. Optimisation of antimicrobial therapy using pharmacokinetic and pharmacodynamic parameters. Clin Microbiol Infect. 2001;7(11):589-96.

22. Levison ME، Levison JH. Pharmacokinetics and pharmacodynamics of antibacterial agents. Infect Dis Clin North Am. 2009;23(4):791-815.

23. Bergstrom CT, Lo M, Lipsitch M. Ecological theory suggests that antimicrobial cycling will not reduce antimicrobial resistance in hospitals. Proc Nat Acad Sci. 2004;101(36):13285-90.

24. Sandiumenge A, Diaz E, Rodriguez A, Vidaur L, Canadell L, Olona M, et al. Impact of diversity of antibiotic use on the development of antimicrobial resistance. J Antimicrob Chemother. 2006:57(6):1197-204.

25. Bonhoeffer S, Lipsitch M, Levin BR. Evaluating treatment protocols to prevent antibiotic resistance. Proc Nat Acad Sci. 1997;94(22):12106-11.

26. Zou L-K, Li L-W, Pan X, Tian G-B, Luo Y, Wu Q, et al. Molecular characterization of $\beta$-lactam-resistant Escherichia coli isolated from Fu River, China. World J Microbiol Biotechnol. 2012;28(5):1891-9.

27. Coleman K, Levasseur P, Girard A-M, Borgonovi M, Miossec C, Merdjan $H$, et al. Activities of ceftazidime and avibactam against $\beta$-lactamaseproducing Enterobacteriaceae in a hollow-fiber pharmacodynamic model. Antimicrob Agent Chemother. 2014;58(6):3366-72.

28. Poole K. Resistance to $\beta$-lactam antibiotics. Cell Mol Life Sci. 2004:61(17):2200-23.

29. Franceschini N, Segatore B, Perilli M, Vessillier S, Franchino L, Amicosante G. Meropenem stability to $\beta$-lactamase hydrolysis and comparative in vitro activity against several $\beta$-lactamase-producing Gram-negative strains. J Antimicrob Chemother. 2002:49(2):395-8.

30. Nicoletti G, Russo G, Bonfiglio G. Recent developments in carbapenems. Expert Opin Investig Drug. 2002:11(4):529-44.

31. Aathithan S, French GL. Prevalence and role of efflux pump activity in ciprofloxacin resistance in clinical isolates of Klebsiella pneumoniae. Eur J Clin Microbiol Infect Dis. 2011:30(6):745-52.

32. Louw GE, Warren RM, Gey van Pittius NC, Leon R, Jimenez A, HernandezPando $R$, et al. Rifampicin reduces susceptibility to ofloxacin in rifampicinresistant Mycobacterium tuberculosis through efflux. Am J Respir Crit Care Med. 2011;184(2):269-76.

33. Askoura M, Mottawea W, Abujamel T, Taher I. Efflux pump inhibitors (EPIs) as new antimicrobial agents against Pseudomonas aeruginosa. Libyan J Med. 2011;6:5870

34. Sun J, Deng Z, Yan A. Bacterial multidrug efflux pumps: mechanisms, physiology and pharmacological exploitations. Biochem Biophys Res Commun. 2014;453(2):254-67.

35. Blanco P, Hernando-Amado S, Reales-Calderon J, Corona F, Lira F, Alcalde-Rico M, et al. Bacterial multidrug efflux pumps: much more than antibiotic resistance determinants. Microorganisms. 2016:4(1):14

\section{Submit your next manuscript to BioMed Central and we will help you at every step:}

- We accept pre-submission inquiries

- Our selector tool helps you to find the most relevant journal

- We provide round the clock customer support

- Convenient online submission

- Thorough peer review

- Inclusion in PubMed and all major indexing services

- Maximum visibility for your research

Submit your manuscript at www.biomedcentral com/submit
C BioMed Central 